\title{
Simulation of Reflooding on Two Parallel Heated Channel by TRACE
}

\author{
Md. Ghulam Zakir \\ Department of Nuclear Engineering, Chalmers University of Technology, Gothenburg, Sweden \\ Corresponding author: paban81@gmail.com
}

\begin{abstract}
In case of Loss-Of-Coolant accident (LOCA) in a Boiling Water Reactor (BWR), heat generated in the nuclear fuel is not adequately removed because of the decrease of the coolant mass flow rate in the reactor core. This fact leads to an increase of the fuel temperature that can cause damage to the core and leakage of the radioactive fission products. In order to reflood the core and to discontinue the increase of temperature, an Emergency Core Cooling System (ECCS) delivers water under this kind of conditions. This study is an investigation of how the power distribution between two channels can affect the process of reflooding when the emergency water is injected from the top of the channels. The peak cladding temperature (PCT) on LOCA transient for different axial level is determined as well. A thermal-hydraulic system code TRACE has been used. A TRACE model of the two heated channels has been developed, and three hypothetical cases with different power distributions have been studied. Later, a comparison between a simulated and experimental data has been shown as well.
\end{abstract}

\section{INTRODUCTION}

Nuclear energy has become an important part of world electricity generation system. A reasonable portion of total world electricity demand is fulfilled by approximately 440 nuclear reactors located all around the world [1].Almost half of this number of reactors will operate for several decades in the future. The energy demand in both developed and developing countries will be doubled by the end of 2030 and electricity consumption will increase by $50 \%$ [2]. The situation will be critical in developing countries where energy crisis results in economic problems, poverty as well as low life standards. Nuclear power can make a significant contribution to eliminate $t h$ is energy crisis with $i t s$ low running cost and energy security. In addition to this, abundance of natural uranium resource is 14.8 million tons which can provide nuclear energy for the next 270 years [3]. Furthermore, technical advancements can enhance the efficiency of nuclear power plants and spent nuclear fuel reprocessing techniques can solve the economic problems if Uranium price goes high. So far several technologies have been implemented to convert the nuclear energy into electrical energy. However, light water reactor (LWR) technologies, pressurized water reactor (PWR) and boiling water reactor (BWR), have become well-known since these technologies are u s e d in the majority of power plants of USA and France [4].

Several features such as safe nuclear operation, lower radiation dose to the workers and lower probability of accident in nuclear reactor can make this technology more reliable than before. Safety is one of the fundamental requirements for development and expansion of nuclear industry. The Safety of nuclear power plants (NPPs) is not only related to safe nuclear operation but also associated with minimizing the consequence of severe nuclear accidents. Nuclear reactor safety is based on the concept of defense-in-depth [5]. One of the crucial aspects in nuclear power plant safety involves the analysis of large break loss-of-coolant accidents (LOCAs). In this kind of scenario, the inventory of core coolant is lost from a break in one of the main pipes. Thus the heat generated because of the decay of the fission products in the core cannot be removed and the temperature of the fuel rods increases. In order to avoid 
severe damage of the core, an emergency core cooling system (ECCS) is used to provide water on the core. The water delivered by this safety system can stop the temperature increase in the core, and prevent the core from melting. In BWRs the emergency water can be injected from the top of the core, so that the core can be reflooded and the cooling of the fuel rods can occur.

\section{CONSERVATION EQUATIONS}

Two phase flow equations are composed of mass, energy and momentum conservation for two particular field. The heat transfer from metal surface to the two phase fluid is described by several time and volume averaged equations. Those equations are:

\subsubsection{Time averaged mass equations.}

$$
\begin{aligned}
& \frac{\partial\left[(1-\alpha) \bar{\rho}_{l}\right]}{\partial t}+\nabla \cdot\left[(1-\alpha) \bar{\rho}_{l} \overrightarrow{\vec{v}}_{l}\right]=-\Gamma \\
& \frac{\partial\left(\alpha \bar{\rho}_{g}\right)}{\partial t}+\nabla \cdot\left[\alpha \bar{\rho}_{g} \overrightarrow{\vec{v}}_{g}\right]=\Gamma
\end{aligned}
$$

\subsubsection{Time Averaged Energy Equations.}

$$
\begin{gathered}
\frac{\partial\left[(1-\alpha) \overline{\rho_{l}} \overline{\left(e_{l}+\frac{v_{l}^{2}}{2}\right)}\right]}{\partial t}+\nabla \cdot\left[(1-\alpha) \bar{\rho}_{l} \overline{\left(e_{l}+\frac{v_{l}^{2}}{2}\right) \overrightarrow{\vec{v}}_{l}}\right]=-\nabla\left[(1-\alpha) \overrightarrow{\bar{q}}_{l}^{\prime}\right]+\nabla \cdot\left[(1-\alpha)\left(\overline{T_{l} \cdot \vec{V}_{l}}\right)\right]+(1-\alpha) \bar{\rho}_{l} \overline{g \cdot \vec{V}_{l}}-\bar{E}_{i}+\overline{q_{d l}} \\
\frac{\partial\left[\alpha \bar{\rho}_{g} \overline{\left(e_{g}+\frac{v_{g}^{2}}{2}\right)}\right]}{\partial t}+\nabla \cdot\left[\alpha \bar{\rho}_{g} \overline{\left(e_{g}+\frac{v_{g}^{2}}{2}\right) \overrightarrow{\vec{v}}_{g}}\right]=-\nabla\left[\alpha \overrightarrow{\bar{q}}_{g}^{\prime}\right]+\nabla \cdot\left[\alpha\left(\overline{T_{g} \cdot \vec{V}_{g}}\right)\right]+\alpha \bar{\rho}_{g} \overline{g \cdot \vec{V}_{l}}+\bar{E}_{i}+\overline{q_{d g}}
\end{gathered}
$$

\subsubsection{Time Averaged Momentum Equations.}

$$
\begin{gathered}
\frac{\partial\left[(1-\alpha) \overline{\bar{v}}_{l} \overline{\vec{v}}_{l}\right]}{\partial t}+\nabla \cdot\left[(1-\alpha) \bar{\rho}_{l} \overline{\overrightarrow{\bar{v}}_{l} \overrightarrow{\vec{v}}_{l}}\right]=\nabla\left[(1-\alpha) \bar{T}_{l}\right]+(1-\alpha) \bar{\rho}_{l} \vec{g}-\bar{M}_{i} \\
\frac{\partial\left[\alpha \bar{\rho}_{g} \overline{\vec{v}}_{g}\right]}{\partial t}+\nabla \cdot \alpha \bar{\rho}_{g} \overline{\overrightarrow{\vec{v}}_{g} \overrightarrow{\vec{v}}_{g}}=\nabla\left[\alpha \bar{T}_{g}\right]+\alpha \bar{\rho}_{g} \vec{g}+\bar{M}_{i}
\end{gathered}
$$

In the above two equations, $\bar{M}_{i}$ represents time averaged interface jump condition to transfer momentum. 


\subsubsection{Volume Averaged Mass Equations.}

$$
\begin{aligned}
& \frac{\partial \overline{\left[(1-\alpha) \rho_{l}\right]}}{\partial t}+\overline{\nabla \cdot\left[(1-\alpha) \rho_{l} \overrightarrow{\vec{v}}_{l}\right]}=-\bar{\Gamma} \\
& \frac{\partial\left(\overline{\left.\alpha \rho_{g}\right)}\right.}{\partial t}+\nabla \cdot \overline{\left.\alpha \rho_{g} \overrightarrow{\vec{v}}_{g}\right]}=\bar{\Gamma}
\end{aligned}
$$

\subsubsection{Volume Averaged Energy Equations.}

$$
\begin{aligned}
& \frac{\partial\left[\overline{\left.(1-\alpha) \rho_{l}\left(e_{l}+\frac{v_{l}^{2}}{2}\right)\right]}\right.}{\partial t}+\nabla \cdot\left[(1-\alpha) \rho_{l}\left(e_{l}+\frac{v_{l}^{2}}{2}+\frac{P}{\rho_{l}}\right) \overrightarrow{\vec{v}}_{l}\right] \\
& =\overline{-\nabla\left[(1-\alpha) \overrightarrow{\bar{q}}_{l}^{\prime}\right]}+\nabla \cdot\left[(1-\alpha)\left(\overline{T_{l} \cdot \vec{V}_{l}}\right)\right]+\overline{(1-\alpha) \rho_{l} g \cdot \vec{V}_{l}-\Gamma h_{l}^{\prime}+W_{l}}+\overline{q_{d l}} \\
& \frac{\partial\left[\alpha \rho_{g}\left(e_{g}+\frac{v_{g}^{2}}{2}\right)\right]}{\partial t}+\overline{\nabla \cdot\left[\alpha \rho_{g}\left(e_{g}+\frac{v_{g}^{2}}{2}+\frac{P}{\rho_{g}}\right) \overrightarrow{\vec{v}}_{g}\right]} \\
& =\overline{-\nabla\left[\alpha \overrightarrow{\bar{q}}_{g}^{\prime}\right]}+\overline{\alpha \rho_{g} g \cdot \vec{V}_{g}}+\overline{\Gamma h_{v}^{\prime}+W_{g}}+\overline{q_{d g}}
\end{aligned}
$$

\subsubsection{Volume Averaged Momentum Equations.}

$$
\begin{aligned}
& \frac{\partial \overline{\left[\overline{\left.(1-\alpha) \rho_{l} \overrightarrow{\vec{v}}_{l}\right]}\right.}}{\partial t}+\overline{\nabla \cdot\left[(1-\alpha) \rho_{l} \overrightarrow{\bar{v}}_{l} \overrightarrow{\bar{v}}_{l}\right]}=\overline{\nabla\left[(1-\alpha) R_{l}\right]}+\overline{(1-\alpha) \rho_{l} \vec{g}-M_{l}} \\
& \frac{\partial \overline{\left[\rho_{g} \vec{v}_{g}\right]}}{\partial t}+\overline{\nabla \cdot\left[\alpha \rho_{g} \overrightarrow{\bar{v}}_{g} \overrightarrow{\bar{v}}_{g}\right]}=\overline{\nabla\left[\alpha R_{g}\right]}+\overline{\alpha \rho_{g} \vec{g}}+\bar{M}_{i}
\end{aligned}
$$

Physical correlations are implemented so that the interaction between vapor and liquid phase and heat transfer at the wall can be taken into account [8]. In addition, special models are also included in order to describe special phenomena such as, critical heat flux or counter current flow limitation.

\section{SIMULATION PROCEDURE}

An input model has been developed to study the reflooding phase of LOCA conditions in a BWR. The input model consists of necessary information of the thermal hydraulic components to obtain a certain condition in a BWR. Furthermore, the TRACE code offers several options to obtain more precise and accurate result. All the components and options used in the model are discussed in this portion.

The entire project has been considered as a hypothetical system. Such a system consists of two parallel, vertical, heated channels that resemble two simplified BWR fuel assemblies. In fact the rod bundle used in the GOTA experiments was simulated as bundle similar to BWR [9].

The TRACE model of the hypothetical system is such that:

- $\quad$ A FILL is used to deliver water under normal conditions, from the bottom.

- The FILL component is connected to a lower pipe and this pipe delivers water to the two heated channels through the lower plenum.

- The heated channels are modeled with two PIPE components associated to their own heat structures and power components.

- The heated water is collected from the outlet of the heated channels into the upper PLENUM.

- The upper PLENUM is connected to the upper PIPE, and the PIPE is connected to a pressure boundary condition given by a BREAK component.

- The injection of the emergency coolant from the top of the system is modeled with a FILL component connected to the upper PIPE, and the BREAK component for the pressure boundary condition is connected to the lower PIPE [10]. Entire model is shown in figure: 2 
Therefore the model consists of in total 16 components. In total four PIPE components, two FILL components, two BREAK components, two heat structures (HTSTR) and two power components have been used in the model. The PIPE component placed on the top is used to maintain thermos-hydraulic flow among FILL, BREAK and PLENUM components and main two PIPE components are used to maintain thermal hydraulic flow between the upper PLENUM and lower PLENUM, another PIPE component on bottom is used to maintain the thermal hydraulic flow among FILL, BREAK and PLENUM components. The two heat structures (HTSTR component) maintain thermal coupling between coolant flows along the channels with two fuel assemblies. All the heat structures and PIPE components are divided into 24 cell volumes. Each fuel assembly contains in total 64 rods. Two adjacent fuel assemblies is shown in figure 1 .

TABLE 1:The materials used for building fuel assembly .

\begin{tabular}{|c|c|}
\hline Name of the components & Materials \\
\hline Fuel rod pin & $\begin{array}{c}\text { NiCr,Boron Nitride and } \\
\text { Inconel-600 }\end{array}$ \\
\hline $\begin{array}{c}\text { Inner channel wall (assumed } \\
\text { but no heat structure been used) }\end{array}$ & Zircaloy \\
\hline
\end{tabular}

TABLE 2: All initial parameters used in the model.

\begin{tabular}{|c|c|}
\hline Parameter & Nominal \\
\hline $\begin{array}{c}\text { Initial two bundle power on } \\
\text { steady state(KW) }\end{array}$ & 300 \\
\hline $\begin{array}{c}\text { Inlet flow rate on steady } \\
\text { state }(\mathrm{kg} / \mathrm{s})\end{array}$ & 7.0 \\
\hline $\begin{array}{c}\text { Inlet flow rate on transient } \\
\text { state }(\mathrm{kg} / \mathrm{s})\end{array}$ & 0.5 \\
\hline $\begin{array}{c}\text { Outlet Pressure boundary } \\
\text { condition }(\mathrm{MPa})\end{array}$ & 0.1 \\
\hline $\begin{array}{c}\text { Inlet water temperature on } \\
\text { steady state }\left({ }^{\circ} \mathrm{C}\right)\end{array}$ & 90 \\
\hline Steam venting & Top \\
\hline
\end{tabular}

The FILL component is connected with the PLENUM by a PIPE component since the FILL component cannot be connected with the PLENUM component directly. Two BREAK components are used in this model: one for outlet boundary condition of coolant flow in steady state condition and another one for outlet boundary condition for coolant flow on reverse direction during the transient state. The following assembly was considered for simulation presents Inconel-600 and boron nitride.
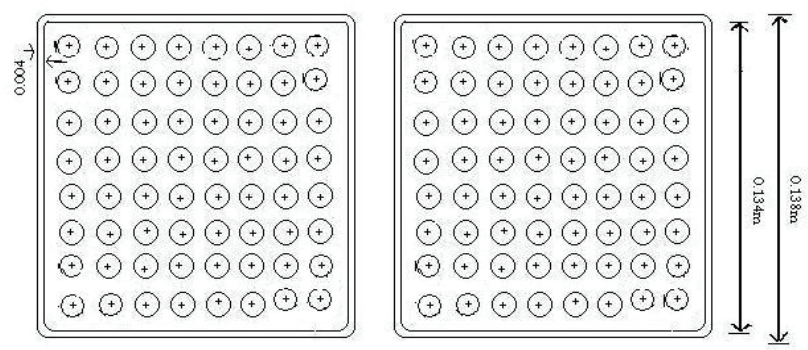

FIGURE 1: Top view of two parallel channels heated by fuel assembly.

For the critical heat flux, the AECL-IPPE CHF table was used, where the quality is estimated from the CISE-GE correlation. The critical heat flux is an important issue in the current context since it is related to the possible boiling crisis that a channel may suffer because of the degradation of the mass flow rate due to the loss of coolant [11]. 
For the counter-current flow limitation (CCFL), the Kutateladze correlation was used [9].

$$
K_{g}^{\frac{1}{2}}+m_{k} K_{f}^{1 / 2}=C_{K}
$$

If we consider the reflooding from the top of the channels, the CCFL is related to the fact that the main emergency flow that moves downwards is limited by a flow of steam moving upwards.

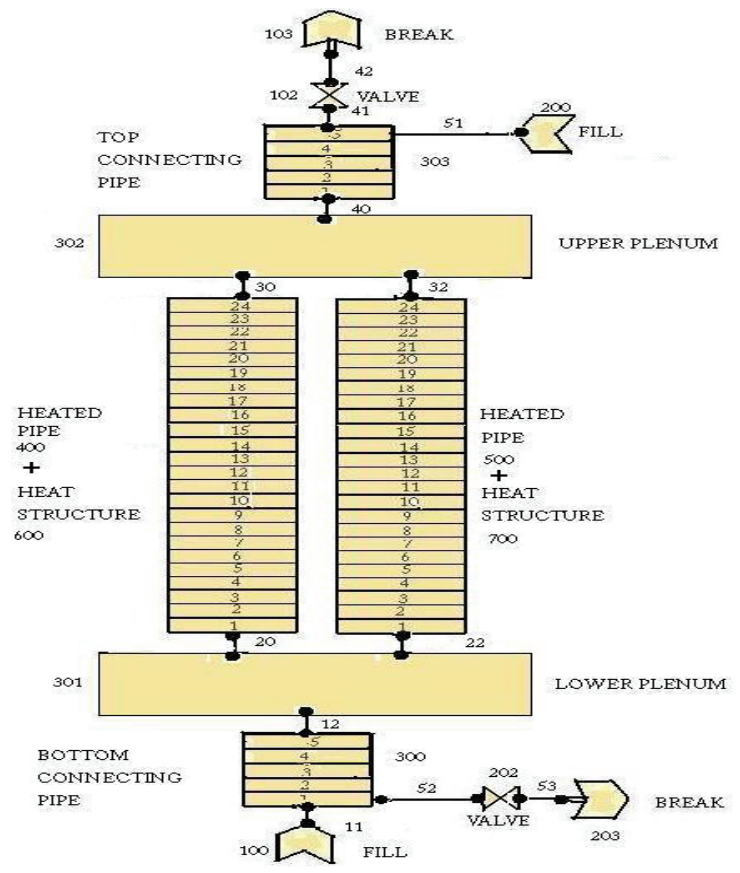

FIGURE 2: Entire thermal hydraulic model for two channel of BWR.

\subsection{Simplifications Used in the Model}

- Heated rods are all the same.

- No radial power distribution (no use of radial peaking factor).

- Axial power profile is considered uniform.

\subsection{Limitations of the model}

- Bypass channel is not included with the model.

- Axial conduction is not taken into account.

- $\quad$ Radiation from the heat structures is not been included.

- No shroud is included.

- Pressure is assumed to be constant with respect to time.

\section{RESULTS}

The objective of this work is to perform a preliminary study of the effect of the power distribution between two heated channels on the reflooding phase of a possible LOCA. Based on the assumptions, the input file was prepared to run the TRACE code. 


\subsection{Description of the Analyzed Cases .}

Three different cases are simulated with different power levels (see the table 4.1).

TABLE 3: Initial power for the two heated channels.

\begin{tabular}{|c|c|c|}
\hline \multirow{2}{*}{ Case } & \multicolumn{2}{|c|}{ Initial power [kW] } \\
\cline { 2 - 3 } & $\begin{array}{c}\text { Heated } \\
\text { channel 1 }\end{array}$ & $\begin{array}{c}\text { Heated } \\
\text { channel 2 }\end{array}$ \\
\hline 1 & 300 & 300 \\
\hline 2 & 300 & 295 \\
\hline 3 & 300 & 290 \\
\hline
\end{tabular}

Two different power components are used to heat up the channels.

All simulation of the 3 cases is performed in two steps. First step is defined as steady state when emergency cooling system is turned OFF and the coolant flows from the bottom to upward direction and in the second step coolant upward flow is stopped, thus, the transient state appears and emergency cooling system is turned ON to recover from the transient state. More precisely it could be explained that in the first step, spray cooling system kept OFF and the entire hypothetical test facility is operated in the steady state condition and after a while, the transient state is initiated. The spray cooling system is initiated when cladding temperature reaches the peak after 100 seconds of dry state. In the final step, coolant flow is initiated from the top and continued for 2700 seconds, however, in transient state the coolant flows in the opposite direction compared to the flow direction in steady state, meanwhile, coolant flow by FILL-100 from the bottom in steady state is kept OFF. Different states, time periods and state durations are mentioned in TABLE 4.

First, the steady state is obtained with constant boundary conditions and constant initial power.

TABLE 4: Different states, the time period and mass flow rate on different states.

\begin{tabular}{|c|l|l|l|}
\hline State & $\begin{array}{l}\text { Time period } \\
{[\boldsymbol{s}]}\end{array}$ & $\begin{array}{l}\text { State Duration } \\
{[\boldsymbol{s}]}\end{array}$ & $\begin{array}{l}\text { Flow Rate } \\
{[\mathbf{K g} / \boldsymbol{s}]}\end{array}$ \\
\hline Steady state & $0.0-200.0$ & 200.0 & 7.0 \\
\hline $\begin{array}{c}\text { Transient } \\
\text { state }\end{array}$ & $200.1-300.0$ & 100.0 & 0.0 \\
\hline $\begin{array}{c}\text { Obtaining the } \\
\text { steady state } \\
\text { from transient } \\
\text { state }\end{array}$ & $300.0-$ & 2700.0 & -0.5 \\
\hline
\end{tabular}

On last column of TABLE 4 the negative sign refers to the reverse direction of the flow. The fuel pin surface temperatures have been calculated by TRACE code for the following cases.

\subsection{Case $1(300-300 \mathrm{~kW})$.}

The upper part of the rod is cooled before the lower part of heat structure (HTSTR-600), at the axial levels 6, 12, 18, 24 and the surface temperature of the rod reaches to the saturation temperature of the fluid. The same plot is with outer surface rod temperature for heat structures (HTSTR-700), at the same axial levels. As expected, the two heat structures have the same behavior since the two heated channels are equally powered. The results are shown in FIGURE 3. 


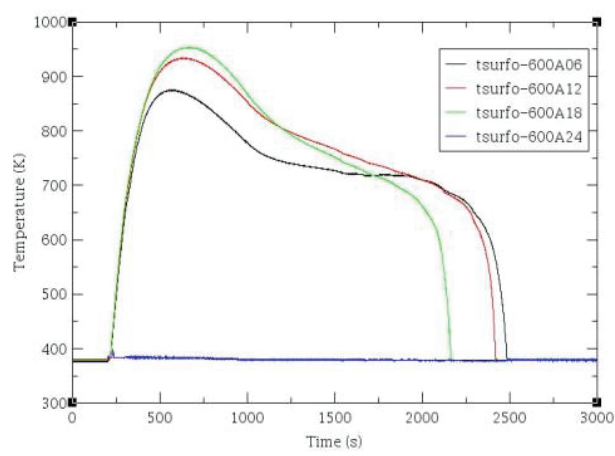

(a)

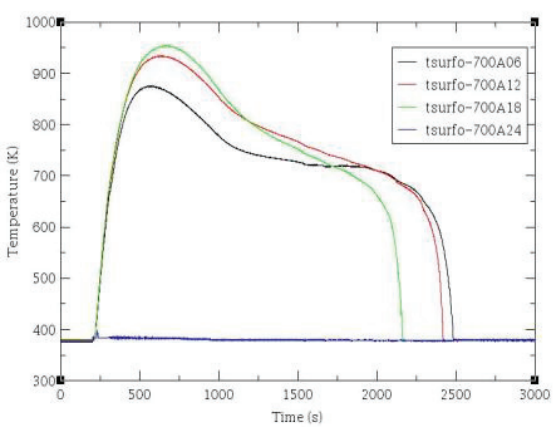

(b)

FIGURE 3: Fuel outer surface temperature on transient state condition for case 1.

\subsection{Case $2(300-295 \mathrm{~kW})$.}

Mass flow rate for pipes 400 and 500 at axial level 12 shows that in the colder channel the mass flow rate is larger (in absolute value).The plots show the outer surface fuel temperature for heat structures 600 and for heat structure 700 , at the axial levels 6,12 , 18,24 . Those plots show that the upper part of the rod is cooled before the lower part. The outer surface temperature for HTSTR700 reaches the saturation earlier than the HTSTR-600.The results are shown in following FIGURE 4.

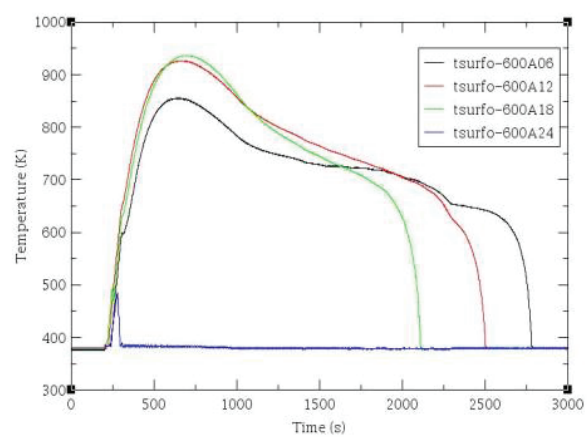

(a)

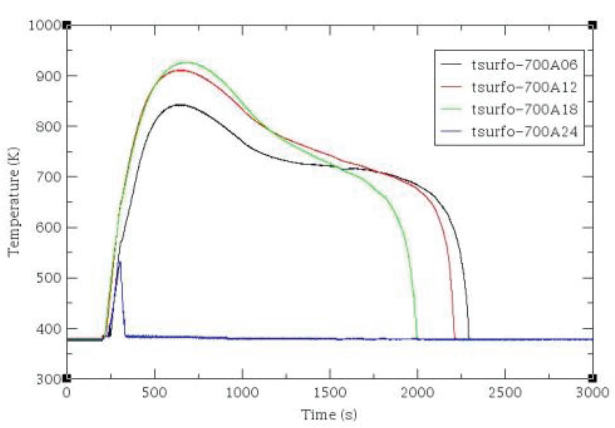

(b)

FIGURE 4: Fuel outer surface temperature on transient state condition for case 2.

\subsection{Case $3(300-290 \mathrm{~kW})$}

Heat structure (HTSTR-600): the same plot includes the outer surf rod temp at axial level 6, 9, 12. It shows that the outer surface rod temperature at level 6 and 9 does not reach the saturation temperature of the fluid, while it does at level 12 . This is the hotter rod, the rod at higher power $(300 \mathrm{~kW})$. Again, the upper part of the rod is cooled earlier than the lower part.

Heat structure (HTSTR-700): the same plot includes the outer surf rod temp at axial level 6, 9, 12. The point is that these temperatures decrease to the saturation temperature of the fluid. This is the rod at lower power $(290 \mathrm{KW})$. Again, the upper part of the rod is cooled earlier than the lower part.

Since, PIPE 500 has a higher mass flow rate than Pipe 400, so the associated rod HTSTR 700is better cooled. 


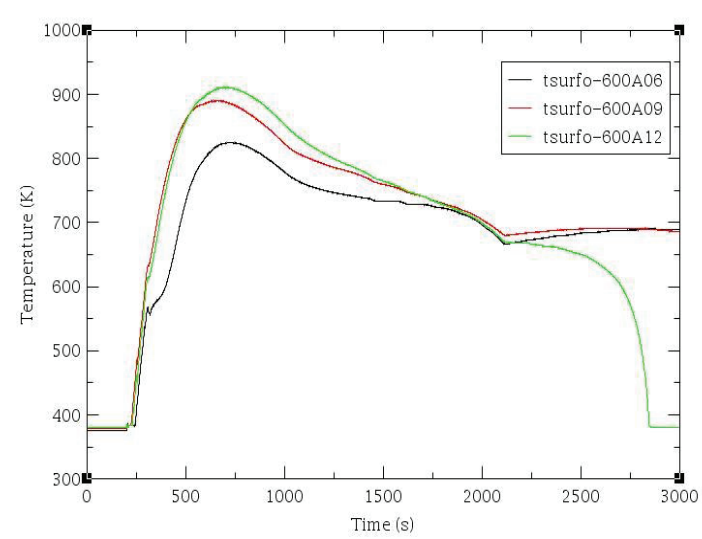

(a)

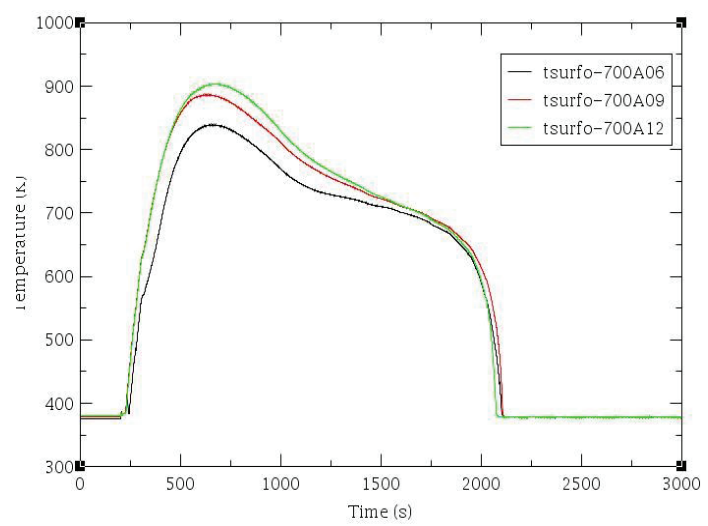

(b)

FIGURE 5: Fuel outer surface temperature on transient state condition for case 3.

\subsection{Comparison of temperature profile.}

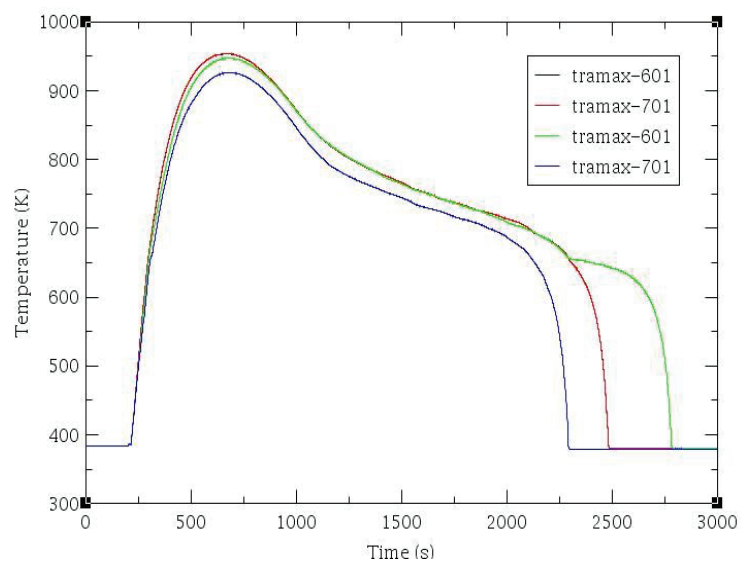

FIGURE 6: The comparison between the max average temperature by power component 601 and power component 701 for the cases $1(300-300 \mathrm{~kW})$ and $2(300-295 \mathrm{~kW})$.

In FIGURE 6, maximum average temperature (tramax) of a particular fuel assembly is presented. Black and red curves indicate the maximum average temperature for case 1 and green and blue curves indicate the maximum average temperature for case 2 . The black curve is not visible since the delivered power for two distinct fuel assemblies are same.

In case 1 and case 2, the surface rod temperature is approximately reduced to the saturation temperature of the coolant; in case 2 , this reduction occurs later for the hotter channel. 


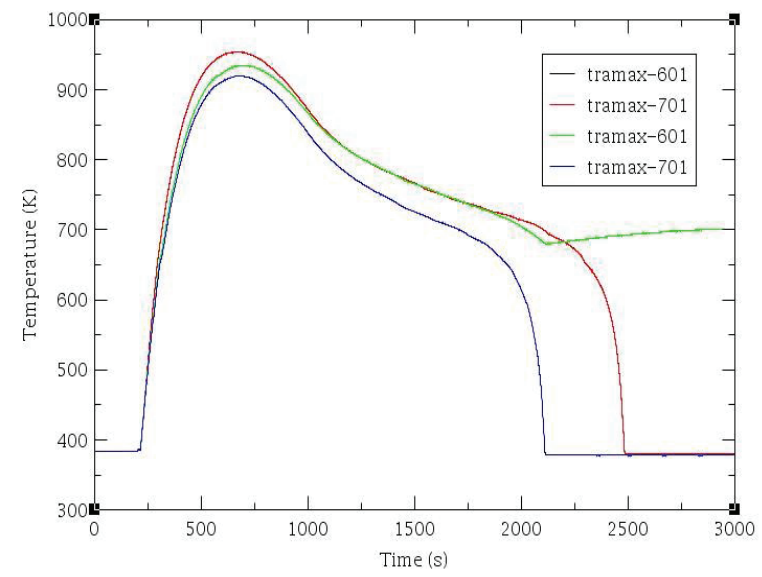

FIGURE 7: The comparison between the max average temperature by power component 601 and component 701 for the cases 1 (300-300) and 3 (300-290).

In FIGURE 7, black and red curve indicate the max average temperature of two fuel assemblies for case 1 and green and blue curve indicate the max average temperature for case 3. The black curve is not visible since the delivered power for two distinct fuel assemblies for case 1 are same.

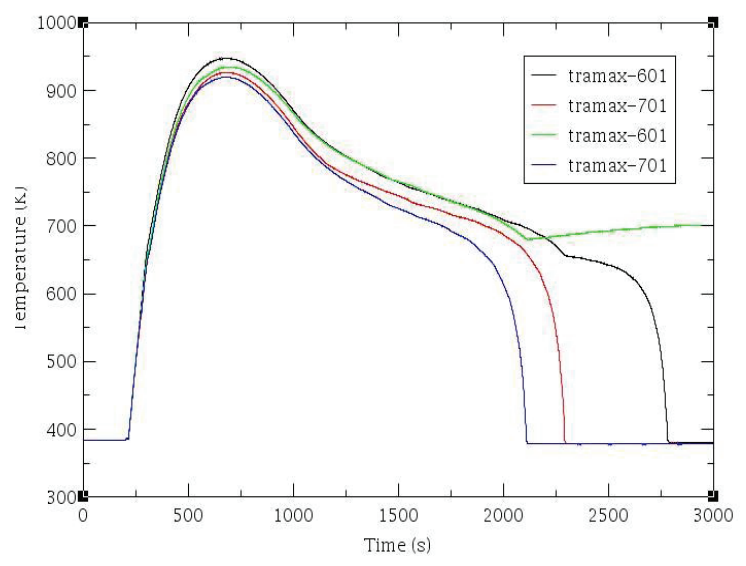

FIGURE 8: The comparison between the max average temperature by power component 601 and component 701 for the cases 2 (300-295) and 3 (300-290).

In FIGURE 8, black and red curve indicate the max average temperature of two fuel assemblies for case 2 and green and blue curve indicate the maximum average temperature of two fuel assemblies for case 3 .

In case 2 , the surface rod temperature is approximately reduced to the saturation temperature of the coolant within the calculation time of 3000 seconds; in case 3 , it does not occur for the hotter channel and the mass flow rate is smaller. 


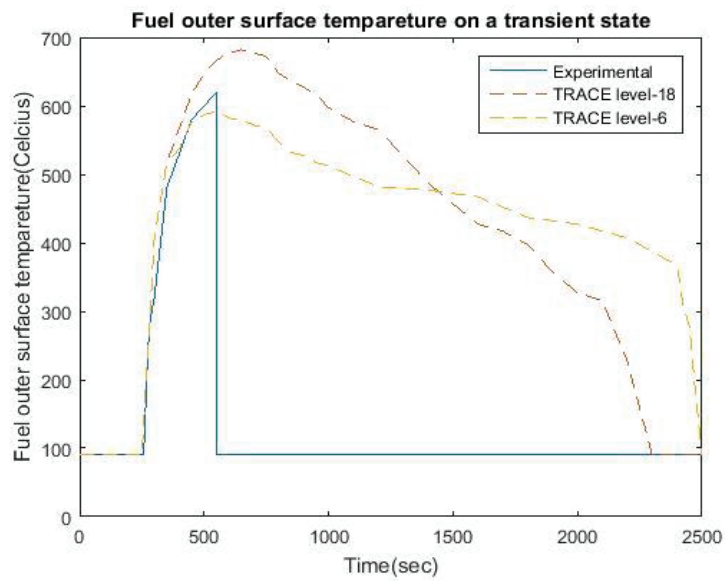

FIGURE 9: Comparison between experimental and simulation data of fuel outer surface temperature.

It is shown from the above FIGURE 9 that the fuel outer surface temperature is quiet reasonable since curve from experimental data exists between two simulated curves of different level. The experimental data is found a test of STUDSVIK/E4-78/68 [12].

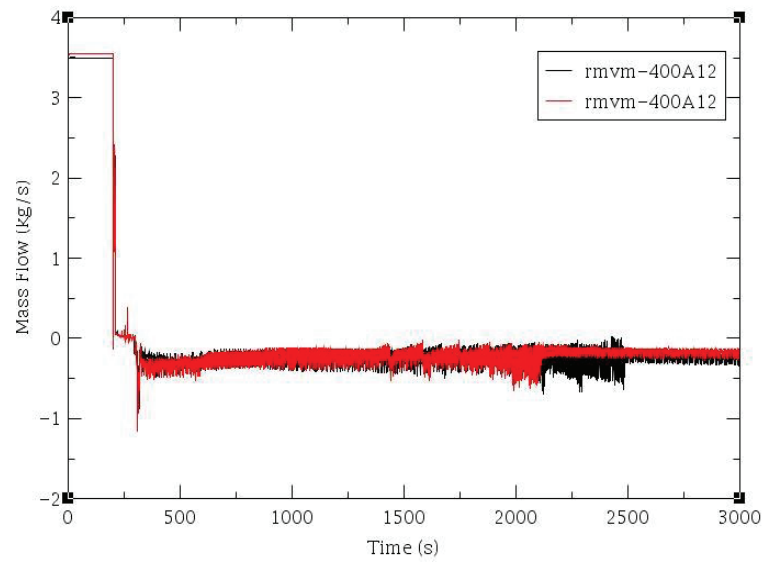

FIGURE 10: The comparison between the mass flow rate of PIPE 400, at axial level 12, for the cases 1 (300-300) and 3 (300290).

In FIGURE 10, legend rmvm refers to mass flow rate along a particular channel .400 and 12 respectively refers to the PIPE component number and level number of the component. Black and red curves consecutively indicate the mass flow rate for case 1 and case 3 .

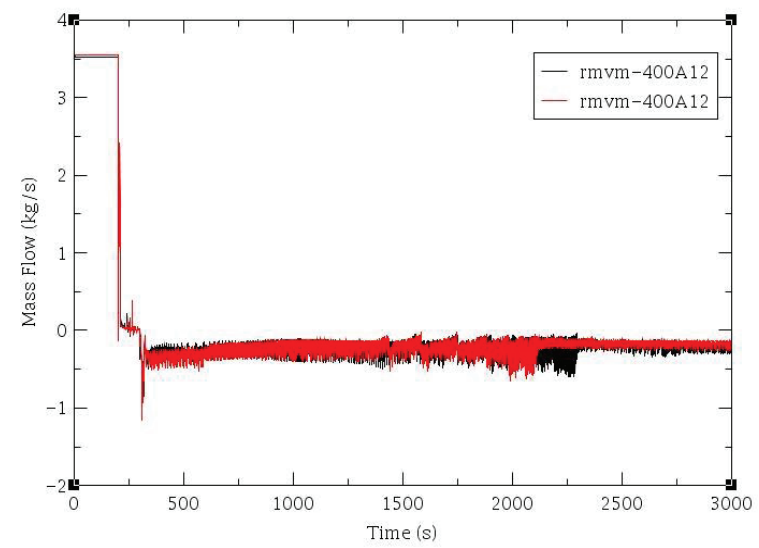

FIGURE 11: The comparison between the mass flow rate of pipe 400, at axial level 12, for the cases 2 (300-295) and 3 (300290).

In FIGURE 11, black and red curve consecutively indicate the mass flow rate for case 2 and case 3. 
The point is that power differences between the two heated channels lead to differences in the mass flow rates to the channels. This, in turn, affects the reflooding process. In comparison with two above figures, more power causes more boiling and counters current flow .As a result, higher range of magnitude is found for case 1, in comparison with case 2 and case 3. Most importantly, the mass flow rate along the channel is negative since flow direction in transient state is opposite to the steady state.

For instance, it is seen that the maximum average temp in the hotter channel of case 2 is reduced to the saturation temperature of the fluid, while it does not happen in case 3 for the hotter channel during the calculation time of 3000 seconds. In fact, even though the total power of case 2 is higher the more even power distribution between the two channels seems to give better conditions for the decrease of temperature in the hotter channel. In fact, the mass flow rate of pipe 400 in case 2 is higher than the mass flow rate of pipe 400 in case 3 .

\section{CONCLUSION}

A simplified model was developed for TRACE computer code for two parallel BWR fuel assemblies with an emergency cooling system injecting water from the top. TRACE model was used for two parallel BWR fuel assemblies with an emergency cooling system injecting water from the top. This is applied to investigate possible effects of different power levels in the two channels, on the evolution of the reflooding phase that follows a loss of coolant. Three cases were analyzed. According to these calculations, it was shown that in cases 1 and 2, where the initial power provided to the two channels is more evenly distributed, the maximum average rod temperature of the hotter channel is quenched and decreases to the saturation temperature of the fluid within the simulation time of 3000 seconds. On the other hand, in case 3, where the difference between the power of the two rod bundles is larger (the initial power in the two channels is equal to 300 and $290 \mathrm{~kW}$, respectively), the temperature of the hotter channel cannot be reduced to the coolant saturation level as quickly as the other cases. However, an extension of this paper could be prepared by addition of sensitivity analysis. Moreover, a bypass channel could be added, radiation from the fuel pin, axial conduction option and a shroud could be included to obtain more accurate result. This simplified model TRACE could be used for other LOCA cases for both BWR and PWR.

\section{ACKNOWLEDGEMENTS}

First of all I would like to thank the almighty for giving me health and strength in my life. My sincerest gratitude goes to my supervisor Professor Paolo Vinai, who has supported me with his extraordinary knowledge and patience throughout my thesis work. He was always there to provide enough guidance and showed me different ways to approach a research problem. His wonderful teaching made me interested in thermohydraulics part of reactor safety system and helped me start this thesis. Without his encouragement and support this research would have not been possible. Moreover, I would like to thank Dr.Manuel Calleja for his valuable comments throughout my research period.

My scholarship program has been funded by Ministry of Science and technology, Bangladesh. I want to thank Mohammad Saifullah, project director of Bangabandhu Fellowship and ICT project for giving me such an opportunity and for monitoring my regular work progress. I would also like to thank Mr. Majharul Habib for his inspiration and motivation throughout this whole period of my MSc degree.

Finally, I would like to thank my elder brother and my parents for supporting me throughout my studies and giving me the moral support to go for the higher studies.

\section{ABBREVIATIONS}

AECL:Atomic Energy of Canada Limited,Canada

BWR: Boiling water reactor

CCFL: Counter current flow

CHF: Critical heat flux

CISE:Common Information Sharing Environment

ECCS: Emergency core cooling system

IPPE:Institue of power and physics,Obnisk, Russia

LOCA: Loss of coolant accident

NPP: Nuclear power plant

PCT: Peak cladding temperature

PWR: Pressurized water reactor

TRACE: TRAC/RELAP Advanced Computational Engine

USNRC:US Nuclear Regulatory Commission 


\section{REFERENCES}

1. Lelieveld, Jos, Daniel Kunkel, and Mark G. Lawrence. "Global risk of radioactive fallout after major nuclear reactor accidents." Atmospheric Chemistry and Physics 12.9 (2012): 4245-4258.

2. SourceOECD . World energy outlook. OECD/IEA, 2006.

3. OECD Nuclear Energy Agency and International Atomic Energy Agency (2006), Uranium 2005: Resources, Production and Demand, OECD, Paris, France.

4. Lester, Richard K., and Mark J. McCabe. "The effect of industrial structure on learning by doing in nuclear power plant operation." The Rand Journal of Economics (1993): 418-438.

5. $\quad$ Sehgal, Bal Raj. "Light water reactor (LWR) safety." Nuclear Engineering and Technology 38.8 (2006): 697.

6. $\quad$ HU, XIAO. "TRACE Analysis of LOCA Transients Performed on FIX-II Facility." (2012).

7. Walls, Robert Allen. Boiling Water Reactor Transient Instability Studies of Ringhals 1 Reactor using TRACE coupled with PARCS. Diss. The Pennsylvania State University, 2009.

8. $\quad$ Bajorek, S. "TRACE V5. 0 Theory Manual, Field Equations, Solution Methods and Physical Models." United States Nuclear Regulatory Commission (2008).

9. Racca, Stefano, and Tomasz Kozlowski. "Trace code validation for BWR spray cooling injection and CCFL condition based on GÖTA facility experiments."Science and Technology of Nuclear Installations 2011.

10. TRACE V5.0 USER'S MANUAL Volume 2 : Modelling Guidelines by United States Nuclear Regulatory Commission .

11 TRACE V5.0 USER'S MANUAL Volume 1 : input specification by United States Nuclear Regulatory Commission. 12. Eriksson, S. O., R. Harju, and R. Pettersson. BWR emergency core cooling investigations. Spray cooling heat transfer experiment in a full scale BWR bundle mock-up. Studsvik Energiteknik AB, Nykoeping (Sweden) 